This is an accepted pre-publication manuscript. For the final version please check the published article and cite as:

Petersen, J, Gibin, M, Mateos, P, Atkinson, P, Longley, P (2011) Names-based classification of accident and emergency department users, Health and Place, in press

\title{
Names-based classification of accident and emergency department users
}

\author{
Jakob Petersen $^{\text {ab }}$, Maurizio Gibin ${ }^{\text {ab }}$, Pablo Mateos ${ }^{\mathrm{a}}$, Philip Atkinson ${ }^{\mathrm{ab}}$, Paul \\ Longley $^{\mathrm{a}^{*}}$
}

${ }^{a}$ Department of Geography and Centre for Advanced Spatial Analysis, University College London, Gower Street, WC1E 6BT, ${ }^{b}$ Southwark Primary Care Trust, Public Health, Neckinger, London SE16 3QN

*Corresponding author: Paul Longley, Department of Geography and Centre for Advanced Spatial Analysis, University College London, Gower Street, WC1E 6BT, Email: plongley@geog.ucl.ac.uk

This paper studies differential healthcare utilisation by ethnic group. Nearly 100,000 users of an Inner London accident and emergency (A\&E) facility were analysed using an innovative names-based ethnicity classification. Adult repeated 'light' usage (i.e. with no hospitalisation or follow-up) did not differ according to ethnic group. Users from ethnic minorities had lower GP registration rates than the majority reference group. However, lack of GP registration was not associated with repeated light use of A\&E, overall. Therefore, these results challenge common perceptions of differential A\&E access rates by ethnicity.

Keywords: Ethnicity, names, accident and emergency, healthcare services, London

\section{Introduction}

National Health Service (NHS) accident and emergency departments (A\&E) offer free access to healthcare and are open 24 hours a day. Southwark Primary Care Trust calculates that the average visit to an A\&E facility costs the NHS three times as much as a visit to a General Practioner (GP). This financial expedient provides a strong incentive for analysis of the cost-effectiveness of care provision if this leads to reductions in the numbers of A\&E visits that can be deemed as inappropriate, non-urgent, convenience- 
oriented, preventable or 'light' (Murphy, 1998a, Murphy, 1998b, Sempere-Selva et al., 2001, Giesen et al., 2006, Leaman et al., 2006).

Segmentation of users according to ethnicity is predicated upon the notion that members of some ethnic groups have utilisation patterns that differ from the general population because of differences in cultural perceptions, language barriers or (particularly for recent migrants) lack of familiarity with the UK National Health Service (NHS) procedures and functions (Hargreaves et al., 2006). Analysis of differences in healthcare utilisation patterns by ethnicity using routinely collected data is far from straightforward, however, because of issues of data incompleteness and quality in spite of the sustained albeit frustrating efforts to extend and improve its coverage (Aspinall, 2000; Kumarapeli et al, 2006; Raleigh, 2008; Sangowawa and Bhopal, 2000). The contribution of this research is to classify individual health records according to patient cultural, linguistic and ethnic group, using information derived from given and family names, in order to increase our understanding of differential healthcare usage by ethnicity. We see this as a contribution to the debate on ethnicity and the utilisation of healthcare (Mladovsky, 2009). In the present study we have analysed GP registration rates and the characteristics of light frequent users of King College Hospital's A\&E department in Inner London. These data have been coded using Onomap, a names-based ethnicity coding tool developed by University College London and applied in Camden and Southwark Primary Care Trusts as well as other public and private organisations (Lakha et al., forthcoming, Mateos, 2007a, Mateos, 2007b). There is a vast literature on the health inequalities of migrant populations; enabled by country of birth information, which is the most widely collected 
information related to ethnicity. Yet, the literature on ethnic health inequalities is relatively recent and scarcer, in the main, due to the fact that monitoring of such inequalities is a recent phenomenon in Britain and almost non-existent in other countries (Mateos, 2007a, Mateos, 2007b). A systematic review of name-based ethnicity classifications found the sensitivity compared to self-reported ethnicity varied between 0.67 and 0.95 , specificity between 0.80 and 1 (Mateos, 2007b). This paper attempts to make a contribution to this scarce literature by proposing an application of a costeffective method to analyse data sets in which ethnicity information is not available. Moreover, when information on country of birth is available, the name methodology can complement the analyses by distinguishing first from subsequent generations. The role of this type of quantitative research is to formulate hypotheses or 'breaking the ground' for more specific and resource-intensive qualitative research.

\section{Methods}

\section{Study area}

King's College Hospital A\&E Department is located in the London Borough of Southwark on the south bank of the River Thames in Central London. Historically Southwark was centrally located in relation to London's port and associated industries. Today, it is among the most deprived local authorities in England, ranking 18th out of 325 local authorities on the income deprivation measure and 25th on the employment deprivation measure (Office for National Statistics, 2008). The majority of patients (66\%) live in areas ranked amongst the $20 \%$ most deprived areas in England. More than $40 \%$ of patients live in publicly rented accommodation; typically social housing apartment blocks built in the 1960s. Southwark has a high population turnover, as well as a diverse and multicultural population. The Borough scores badly on a number of official health 
indicators including high infant mortality, low birth weight, low male life expectancy at birth, low disability-free life expectancy and high teenage conception rates (Petersen et al., 2009). Therefore, the interrelations between these diverse population characteristics and unequal health outcomes make Southwark a unique study area to investigate differential A\&E usage.

\section{Data}

Records for each of the 141,613 A\&E attendances (aka visits) at King's College Hospital A\&E unit during a one-year period (1 April 2005-31 March 2006) were obtained from King's College Hospital NHS Foundation Trust. This facility principally serves the South London Boroughs of Southwark and neighbouring Lambeth and the analyses were restricted to residents living in these two Boroughs.

Most services in the National Health Service (NHS) record information on episodes of care labelled with unique person identifiers (NHS numbers). NHS numbers are issued when patients first register with a GP. However, NHS numbers are often missing from A\&E records, because users can 'walk in' from the street without an appointment, some patients are unconscious or distressed on arrival, and some are not registered with a GP. As a consequence, individuals were identified, for this study by using a combination of date of birth, postcode, and sex in place of a unique identifier (Gill, 1997). This approach was tested using the local GP patient register, where all users are identified using unique NHS numbers. The combination of the three fields correctly identified unique individuals in $99 \%$ of all cases. Using this technique we identified 107,735 users from the 163,333 A\&E attendances collected over that particular year (average 1.5 attendances per user per year). 


\section{Classification of outcome severity}

Many studies have been concerned with identifying A\&E usage that is deemed inappropriate, non-urgent, convenience-oriented, preventable or light (Murphy, 1998a, Murphy, 1998b, Sempere-Selva et al., 2001, Giesen et al., 2006). In this research we have focussed on A\&E outcome categories, because in comparison with other available data (diagnosis, triage, mode of transport) it is recorded at discharge rather than upon arrival (cf. triage) and it was also recorded more comprehensively ( $86 \%$ of attendances) than for any of the other characteristics. We reclassified the outcomes into four major categories of severity by drawing on the expertise of A\&E staff:

(1) Majors containing major operations and emergency admission to hospital (2) Follow-up containing cases where the attendee is referred to another speciality (3) Discharged without follow-up; for those treated and discharged within 4 hours. (4) Did-Not-Wait for those that did not wait to receive attention.

Examples of the Majors category are outcomes coded "Admit", "Gynae scanning", "Theatre" or "Died", indicating: hospitalisation, major complications, redirection to an operating theatre or death, respectively. Follow-up included categories such as "Eye clinic" or "Fracture clinic". Discharged included for instance, "Discharged" or more cryptic categories such as "Taxi". Did-Not-Wait contained the code for this outcome alone. Many of the codes in use required very specific, local knowledge such as the name of particular hospital wing or clinic.

Each of the 107,735 users was subsequently identified by the outcome of their first attendance within the study period resulting in a user classification with Majors (16\%), Follow-up (24\%), Discharged (44\%) or Did-Not-Wait (2\%). Users where the outcome data were missing (14\%) were not analysed further, but resembled the Discharged category in their demographic profile. The analysis was performed on the 
93,096 users with outcome information. To focus on users that potentially could be treated in other healthcare settings we have chosen to assign repeat users, i.e. those that attended two or more times during the one year study period, to the Discharged and DidNot-Wait categories and termed these 13,764 'light frequent users' for the purpose of this study. 'Light' is thus intended as an umbrella term for attendances that did not lead to hospitalisation or follow-up treatment. Non-registration with a GP was assumed where the GP details were either missing or coded as unknown.

\section{Statistical analysis}

Age- and sex-specific attendance rates were calculated as the number of attendances per user. Multiple logistic regression analysis was used to control for a number of potentially confounding factors (Long and Freese, 2006). The following independent categorical variables were included: sex; ethnicity; and area deprivation derived from the 2004 Index of Multiple Deprivation in quintiles (Department for Communities and Local Government, 2004). Ethnicity was assigned based on the user's forename and surname combination using the Onomap names classification software (Lakha et al., forthcoming, Mateos, 2007a). In a small proportion of cases (4.6\%) the Onomap software did not assign the user to a known ethnic group and the user was subsequently assigned to an 'Other' category. The age profile varied significantly across different ethnic groups (likelihood-ratio test of interaction, $\chi^{2}=41.33, \mathrm{df}=24, \mathrm{P}=0.015$ ) and the subsequent analyses were hence stratified by the following age groups: $0-15,16-29,30-44,45+$ years of age. Covariates were analysed for deviation from null using a Wald-test. The logit proportions of users not registered with a GP relative to all GP-registered users were likewise analysed with sex, deprivation and ethnicity as covariates in age stratified 
analyses. All logistic regression models were furnished with Hosmer-Lemeshow goodness-of-fit statistics (in deciles) as to whether predicted values were significantly different from observed values (Long and Freese, 2006).

\section{Results}

Attendances per user were highest amongst the under-1 and 1-4 year olds, but then tailed off only to rise again after 40 years of age for men and age 50 for women (Figure 1).

(Figure 1 - about here)

\section{Light frequent users}

The 13,764 light frequent users accounted for 38,002 attendances $(28.8 \%$ of all attendances). On average, a light frequent user attended A\&E 2.8 times per year; nearly twice the overall average of 1.5 attendances per user per year.

There were more light frequent users among men than women and this gender effect was significant for the 30-44 and 45+ age groups (Table 1). There were more light frequent users in the four most deprived areas; they were $22-31 \%$ more common among $0-15$ year olds, $18-23 \%$ for $30-44$ year olds, and $19-32 \%$ for $45+$ year olds. Ethnic group, determined by ethnicity, was only significant as a covariate for the 0-15 year cohort, where users with names classified as Eastern European (OR 1.58, 95\% CI 1.27-1.98), Hispanic (OR 1.17, 95\% CI 1.03-1.35) and Muslim (OR 1.13, 95\% CI 1.26) were more likely to be repeat users relative to the reference population with English names.

(Table 1 and 2 - about here) 


\section{Non-registration with a GP}

There were 15,062 A\&E users who were not classed as registered with a GP, amounting

to $16 \%$ of users. Non-registration by age group was $6 \%$ for $0-15$ year olds, $30 \%$ for $16-29$ year olds, $19 \%$ for $30-44$ year olds and $9 \%$ for $45+$ year olds. Children of many ethnic minority groups had lower rates of GP-registration relative to those with English (the reference population) or Celtic names (Table 2). Lower rates of registration also persisted for ethnic minorities throughout the adult age groups, especially for the non-British Europeans and other minority name origin groups. Adult men were $39-59 \%$ less likely than women to be registered with a GP in their respective age groups. The effects of area deprivation were relatively weak and did not follow a clear trend. Hypothetically, it might be anticipated that users not registered with a GP would rely on A\&E for nonurgent care needs. However, we found that light frequent users were consistently 25$39 \%$, more likely to be registered relative to all other users.

A more detailed analysis revealed that non-registration with a GP was much more common in users with names associated with EU-15 countries (the fifteen pre-2004 EU Member States) as well as from Eastern Europe and China (see Table 3).

(Table 3 - about here)

\section{Discussion}

A much repeated assertion within the healthcare profession is that many ethnic minority groups are not yet accustomed to the healthcare system and therefore go to A\&E with minor ailments (Hargreaves et al., 2006). Name-based ethnicity coding has been suggested as a way in which local healthcare authorities can identify such user groups 
and design social marketing campaigns to divert them to more cost-effective alternatives (Nanchahal et al., 2001, Leaman et al., 2006). The Inner London location of King's College Hospital A\&E means that it serves a very fluid, diverse and multicultural population. Relating these general area characteristics to patients presenting at $\mathrm{A} \& \mathrm{E}$ facilities is complicated by the lack of population registers with usable information on ethnic group and indicators of local, regional or national residential mobility. The analysis described in this paper offers a way around this methodological problem.

Ethnic group information is routinely collected from users of NHS services, but in the case of $\mathrm{A} \& \mathrm{E}$, missing and inconsistent data often make this source inadequate for analysis. Interestingly, A\&E records are, at the same time, one of the few data sources that are likely to correspond with the de facto population characteristics at any given point in time. Name-based ethnicity classification of populations can in such cases provide a timely insight into questions of population mobility, international migration, utilisation and accessibility of public services, health inequality, and so forth (Mateos, 2007a, Mateos, 2007b). One of the problems with applying name-based ethnicity classifications in these cases, however, is that crude numerical analysis may simply and unjustly encourage the stigmatisation of entire ethnic groups. With this research we have instead tried to focus on healthcare seeking behaviours, specifically of light frequent use of A\&E within a one year time period, and compared this to GP-registration rates within the same population. We have used a novel names-based ethnicity classification to do this (Mateos, 2007a, Mateos, 2007b). The Onomap methodology takes both forename and surname into account when assigning an individual to the most likely group based on culture, ethnicity and linguistic indicators. The classification provides a flexible and 
readily updateable means of assigning ethnic minority groups, where self-reported ethnicity is not available to the desired quality (Mateos, 2007b, Mateos, 2007a, Gibin et al., 2009). Onomap has been evaluated against large population registers where the selfreported ethnicity is available next to a person's name, and preliminary results show an overall specificity and sensitivity around 80-90\% (Lakha et al., forthcoming).

Children under 1 year of age were up to $80 \%$ more likely to be light frequent users relative to the overall average. This result corresponds with the findings of Agran et al. (2003), that children aged 15-17 months have the highest injury rates of all children under 16 years of age. This age period coincides with the time at which most children start to stand up and learn to walk, develop inquisitive behaviour and increase hand-tomouth activity. Agran et al. (2003) showed that the primary causes are, in decreasing order, falls, poisoning, transportation, foreign bodies, and fires and burns. Another potential cause is the incidence of certain early age childhood diseases. Parents are generally thought to be more risk averse with their young children and will go to $\mathrm{A} \& \mathrm{E}$ for reassurance. In this cross-sectional study it is difficult to separate out the somewhat subjectively termed 'worried parent' effect. We concur with view of Murphy (1998a) that any classification of 'inappropriateness' for A\&E attendance is essentially subjective. Infants may, as mentioned above, be taken to $\mathrm{A} \& \mathrm{E}$ as a consequence of higher accident rates for this age group, sudden fevers and other morbidities as well as an actual higher risk of mortality (Gavrilov and Gavrilova, 2001). This suggests that although children are the most frequent light users, there are fundamental principles at work that would make it 
difficult and possibly unethical to reduce this type health seeking behaviour on the basis of cost-cutting.

More men than women fell into the target category of light frequent users in the 30-44 and $45+$ year age groups, although only with a risk difference of 7-8\% (Table 1). The effects for area deprivation were generally weak or did not follow a specific gradient apart from that the most deprived $4 / 5^{\text {th }}$ of the area usually had greater odds ratios than the least deprived quintile. A number of other studies have identified stronger gradients with area deprivation (see e.g. studies in Kendrick et al., 2005). The majority of the population in this study, however, resided in areas ranking amongst the $20 \%$ most deprived nationally. Consequently, the study area has less variation with regards to area deprivation, which is another likely reason for the relatively weak effects of deprivation found in this study.

We identified very few significant differences within this very ethnically diverse user group with regards to light frequent use of A\&E. The exception to the general trend concerned the 0-15 year old age cohort, where users with names classified as Eastern European and some other name minorities were more likely to be repeat users relative to the reference population with English names. Further qualitative research is needed to uncover whether these groups of families have particular needs that should be addressed and whether more could be done to accommodate these potential needs in a primary care setting.

An alternative explanation for the apparent equality in light A\&E usage might be that inner city GP services are not considered equally attractive/acceptable by different ethnic groups. A study by Rajpar et al. (2000) showed that among users of A\&E and out-of- 
hours GP services in inner Birmingham (UK) those of White ethnic background were more likely to use A\&E rather than the GP alternative compared to other ethnic groups.

Low GP registration rates have for years been associated with the fluid populations of inner city areas (Haynes et al., 1995, Hargreaves et al., 2006) and especially among the 20-40 year olds and men more than women (Millett et al., 2005). In this study the level of non-registration was particularly high amongst users with names originating in Poland (51\%) as well as with users from many of the fifteen pre-2004 EU membership countries (25-30\% non-registration). Adult men were also 39-59\% less likely than women to be registered with a GP in their respective age groups (Table 3). Poland is the largest of the ten new Eastern European countries that joined the EU in 2004 and differences in GP-registration rate could be interpreted as an effect of a shorter period of residence for the citizens of the EU accession countries (Leaman et al 2006). Hypothetically users not registered with a GP might rely on A\&E for non-urgent care needs. However, we found that light frequent users were consistently, 25-39\%, more likely to be registered relative to all other users (Table 2). There may be at least two different possible explanations for this. First, it could be interpreted as a type of 'healthy user' bias, i.e. the effect that some patients are more concerned about their health than others, engage in healthier lifestyles and also tend to use the healthcare services more often and more assertively than others. Second, a correlation between health service registration and healthcare seeking behaviour could alternatively be interpreted as a result of a prevalence-incidence bias (Delgado-Rodriguez and Llorca, 2004), where users that are more likely to leave an area also have different healthcare needs and behaviours to those resident for longer periods of time. Although this is an interesting counter- 
hypothesis the actual number of contacts that most users have with the A\&E services are probably too infrequent to fully disentangle such a relationship using routinely collected data for an annual period.

There is a continuing debate about the health of ethnic minorities in general and recent migrants in particular, much of it focused upon access and use of healthcare services. We concur with Mladovsky (2009) about the importance of monitoring equity in these areas. There are many known examples of inequalities, for example in the uptake of vaccination and screening, as well as the use of dental, sexual, mental, inpatient, outpatient, and long-term health care services (Mladovsky, 2009). Yet there are also other examples in which ethnicity or migrant status does not appear to constitute a specific risk factor. The findings from this study enabled the local healthcare authority to focus upon potentially unmet needs of children from ethnic minorities. The results of this research suggest that campaigns to increase GP registrations should not be priorities for resource expenditure.

Names-based ethnicity classifications may present a promising means of updating and informing local healthcare programmes, especially where ethnicity - self-reported or otherwise - is not available to the desired level of granularity or with near complete coverage. We see our approach as a 'first filter' or segmentation method to identify groups with particular needs or behaviours, that can assist health authorities in selecting individuals, for example for focus groups that in turn might garner valuable insights to inform public health campaigns and optimise the use of local healthcare services. The study also highlights some of the pitfalls associated with this type of analysis that users should be aware of. 
Table 1 light frequent usage of A\&E. Multivariable logistic regression analysis stratified by age

\begin{tabular}{|c|c|c|c|c|}
\hline Age strata & Covariates & Level & Odds Ratio & P-value (Wald) \\
\hline \multirow[t]{19}{*}{$0-15 \mathrm{yr}$} & \multirow[t]{3}{*}{ Sex } & & & 0.3802 \\
\hline & & Men & Ref & \\
\hline & & Women & $0.97(0.91-1.04)$ & \\
\hline & \multirow[t]{6}{*}{ Deprivation } & & & $<0.0001$ \\
\hline & & 1st Least & Ref & \\
\hline & & $2^{\text {nd }}$ & $1.31(1.18-1.46)$ & \\
\hline & & $3^{\text {rd }}$ & $1.22(1.10-1.36)$ & \\
\hline & & $4^{\text {th }}$ & $1.25(1.13-1.39)$ & \\
\hline & & 5th Most & $1.22(1.11-1.36)$ & \\
\hline & \multirow[t]{9}{*}{ Ethnicity } & & & $<0.0001$ \\
\hline & & English & Ref & \\
\hline & & African & $0.96(0.86-1.07)$ & \\
\hline & & Celtic & $1.00(0.91-1.09)$ & \\
\hline & & Eastern European & $1.58(1.27-1.98)$ & \\
\hline & & European other & $1.11(0.93-1.32)$ & \\
\hline & & Hispanic & $1.17(1.03-1.35)$ & \\
\hline & & Muslim & $1.13(1.02-1.26)$ & \\
\hline & & Other & $1.18(1.06-1.31)$ & \\
\hline & \multicolumn{4}{|c|}{ Goodness-of-fit: $\mathrm{N}=24,363 ;$ Hosmer-Lemeshow $(\mathrm{df})=2.29(8) ;$ P-value $=0.9707$} \\
\hline Age strata & Covariates & Level & Odds Ratio & P-value (Wald) \\
\hline \multirow[t]{19}{*}{$16-29 \mathrm{yr}$} & Sex & & & 0.9885 \\
\hline & & Men & Ref & \\
\hline & & Women & $1.00(0.93-1.08)$ & \\
\hline & \multirow[t]{6}{*}{ Deprivation } & & & 0.0549 \\
\hline & & 1st Least & Ref & \\
\hline & & $2^{\text {nd }}$ & $1.13(1.00-1.27)$ & \\
\hline & & $3^{\text {rd }}$ & $1.15(1.02-1.29)$ & \\
\hline & & $4^{\text {th }}$ & $1.19(1.06-1.33)$ & \\
\hline & & 5th Most & $1.10(0.98-1.24)$ & \\
\hline & \multirow[t]{9}{*}{ Ethnicity } & & & 0.2873 \\
\hline & & English & Ref & \\
\hline & & African & $1.04(0.89-1.20)$ & \\
\hline & & Celtic & $1.00(0.98-1.24)$ & \\
\hline & & Eastern European & $1.01(0.84-1.20)$ & \\
\hline & & European other & $0.84(0.70-1.00)$ & \\
\hline & & Hispanic & $1.04(0.90-1.21)$ & \\
\hline & & Muslim & $1.08(0.95-1.23)$ & \\
\hline & & Other & $0.91(0.80-1.04)$ & \\
\hline & \multicolumn{4}{|c|}{ Goodness-of-fit: $\mathrm{N}=23,370 ;$ Hosmer-Lemeshow $(\mathrm{df})=3.82(8) ;$ P-value $=0.8727$} \\
\hline Age strata & Covariates & Level & Odds Ratio & P-value (Wald) \\
\hline
\end{tabular}




\begin{tabular}{|c|c|c|c|c|}
\hline \multirow[t]{19}{*}{$30-44$ yr } & \multirow[t]{3}{*}{ Sex } & & & \multirow[t]{3}{*}{0.0436} \\
\hline & & Men & Ref & \\
\hline & & Women & $0.92(0.85-1.00)$ & \\
\hline & \multirow[t]{6}{*}{ Deprivation } & & & 0.0007 \\
\hline & & 1st Least & Ref & \\
\hline & & $2^{\text {nd }}$ & $1.02(0.90-1.16)$ & \\
\hline & & $3^{\text {rd }}$ & $1.18(1.05-1.34)$ & \\
\hline & & $4^{\text {th }}$ & $1.19(1.05-1.34)$ & \\
\hline & & 5th Most & $1.23(1.09-1.39)$ & \\
\hline & \multirow[t]{9}{*}{ Ethnicity } & & & 0.2175 \\
\hline & & English & Ref & \\
\hline & & African & $0.91(0.79-1.06)$ & \\
\hline & & Celtic & $1.03(0.93-1.14)$ & \\
\hline & & Eastern European & $1.03(0.79-1.33)$ & \\
\hline & & European other & $0.84(0.69-1.03)$ & \\
\hline & & Hispanic & $1.07(0.92-1.25)$ & \\
\hline & & Muslim & $1.06(0.92-1.22)$ & \\
\hline & & Other & $0.89(0.76-1.04)$ & \\
\hline & \multicolumn{4}{|c|}{ Goodness-of-fit: $\mathrm{N}=22,787$; Hosmer-Lemeshow $(\mathrm{df})=14.7(8) ;$ P-value $=0.0653$} \\
\hline Age strata & Covariates & Level & Odds Ratio & P-value (Wald) \\
\hline \multirow[t]{18}{*}{$45+\mathrm{yr}$} & Sex & & & 0.0385 \\
\hline & & Men & Ref & \\
\hline & & Women & $0.92(0.84-1.00)$ & \\
\hline & \multirow[t]{6}{*}{ Deprivation } & & & 0.0002 \\
\hline & & 1st Least & Ref & \\
\hline & & $2^{\text {nd }}$ & $1.19(1.05-1.36)$ & \\
\hline & & $3^{\text {rd }}$ & $1.13(0.99-1.29)$ & \\
\hline & & $4^{\text {th }}$ & $1.29(1.13-1.46)$ & \\
\hline & & 5th Most & $1.32(1.16-1.50)$ & \\
\hline & \multirow[t]{9}{*}{ Ethnicity } & & & 0.6415 \\
\hline & & English & Ref & \\
\hline & & African & $1.13(0.93-1.36)$ & \\
\hline & & Celtic & $0.99(0.89-1.10)$ & \\
\hline & & Eastern European & $0.93(0.61-1.41)$ & \\
\hline & & European other & $1.00(0.78-1.30)$ & \\
\hline & & Hispanic & $1.21(0.98-1.49)$ & \\
\hline & & Muslim & $0.98(0.82-1.17)$ & \\
\hline & & Other & $0.98(0.82-1.17)$ & \\
\hline
\end{tabular}


Table 2 GP registration. Multivariable logistic regression analysis of users not registered with a GP. Stratified by age

\begin{tabular}{|c|c|c|c|c|}
\hline Age strata & Covariates & Level & Odds Ratio & P-value (Wald) \\
\hline \multirow[t]{22}{*}{$0-15 \mathrm{yr}$} & \multirow[t]{3}{*}{ Sex } & & & 0.9582 \\
\hline & & Men & Ref & \\
\hline & & Women & $0.92(0.83-1.02)$ & \\
\hline & \multirow[t]{6}{*}{ Deprivation } & & & 0.1426 \\
\hline & & 1st Least & Ref & \\
\hline & & $2^{\text {nd }}$ & $1.20(1.00-1.43)$ & \\
\hline & & $3^{\mathrm{rd}}$ & $1.14(0.97-1.36)$ & \\
\hline & & $4^{\text {th }}$ & $1.08(0.91-1.28)$ & \\
\hline & & 5th Most & $0.92(0.78-1.10)$ & \\
\hline & \multirow[t]{3}{*}{ User category } & & & $<0.0001$ \\
\hline & & Other & Ref & \\
\hline & & Light frequent & $0.61(0.53-0.71)$ & \\
\hline & \multirow[t]{9}{*}{ Ethnicity } & & & $<0.0001$ \\
\hline & & English & Ref & \\
\hline & & African & $1.23(1.02-1.48)$ & \\
\hline & & Celtic & $1.14(0.97-1.34)$ & \\
\hline & & Eastern European & $2.54(1.85-3.49)$ & \\
\hline & & European other & $1.52(1.16-2.00)$ & \\
\hline & & Hispanic & $1.82(1.48-2.24)$ & \\
\hline & & Muslim & $1.40(1.18-1.66)$ & \\
\hline & & Other & $1.53(1.29-1.81)$ & \\
\hline & \multicolumn{4}{|c|}{ Goodness-of-fit: $\mathrm{N}=24,363$; Hosmer-Lemeshow $(\mathrm{df})=2.57(8) ; \mathrm{P}$-value $=0.9582$} \\
\hline Age strata & Covariates & Level & Odds Ratio & P-value (Wald) \\
\hline \multirow[t]{19}{*}{$16-29 \mathrm{yr}$} & \multirow[t]{3}{*}{ Sex } & & & $<0.0001$ \\
\hline & & Men & Ref & \\
\hline & & Women & $0.59(0.56-0.63)$ & \\
\hline & \multirow[t]{6}{*}{ Deprivation } & & & $<0.0001$ \\
\hline & & 1st Least & Ref & \\
\hline & & $2^{\text {nd }}$ & $1.16(1.06-1.26)$ & \\
\hline & & $3^{\text {rd }}$ & $0.90(0.82-0.99)$ & \\
\hline & & $4^{\text {th }}$ & $0.91(0.83-1.00)$ & \\
\hline & & 5th Most & $0.85(0.78-0.94)$ & \\
\hline & \multirow[t]{3}{*}{ User category } & & & $<0.0001$ \\
\hline & & Other & Ref & \\
\hline & & Light frequent & $0.77(0.71-0.84)$ & \\
\hline & \multirow[t]{7}{*}{ Ethnicity } & & & $<0.0001$ \\
\hline & & English & Ref & \\
\hline & & African & $1.01(0.89-1.15)$ & \\
\hline & & Celtic & $1.00(0.92-1.09)$ & \\
\hline & & Eastern European & $5.26(4.61-6.00)$ & \\
\hline & & European other & $2.83(2.50-3.20)$ & \\
\hline & & Hispanic & $2.60(2.33-2.90)$ & \\
\hline
\end{tabular}


$\begin{array}{ll}\text { Muslim } & 1.13(1.02-1.26) \\ \text { Other } & 2.56(2.33-2.82)\end{array}$

Goodness-of-fit: $\mathrm{N}=23,370$; Hosmer-Lemeshow $(\mathrm{df})=15.5(8) ; \mathrm{P}$-value $=0.0502$

\begin{tabular}{|c|c|c|c|c|}
\hline Age strata & Covariates & Level & Odds Ratio & P-value (Wald) \\
\hline \multirow[t]{21}{*}{$30-44$ yr } & Sex & & & $<0.0001$ \\
\hline & & Men & Ref & \\
\hline & & Women & $0.41(0.38-0.44)$ & \\
\hline & Deprivation & & & 0.0343 \\
\hline & & 1st Least & Ref & \\
\hline & & $2^{\text {nd }}$ & $1.06(0.96-1.18)$ & \\
\hline & & $3^{\mathrm{rd}}$ & $0.96(0.86-1.07)$ & \\
\hline & & $4^{\text {th }}$ & $0.96(0.86-1.07)$ & \\
\hline & & 5th Most & $0.89(0.81-1.00)$ & \\
\hline & User category & & & $<0.0001$ \\
\hline & & Other & Ref & \\
\hline & & Light frequent & $0.75(0.68-0.84)$ & \\
\hline & Ethnicity & & & $<0.0001$ \\
\hline & & English & Ref & \\
\hline & & African & $0.95(0.82-1.09)$ & \\
\hline & & Celtic & $0.92(0.83-1.02)$ & \\
\hline & & Eastern European & $3.30(2.74-3.98)$ & \\
\hline & & European other & $1.72(1.48-2.00)$ & \\
\hline & & Hispanic & $2.15(1.91-2.43)$ & \\
\hline & & Muslim & $1.20(1.06-1.36)$ & \\
\hline & & Other & $1.74(1.54-1.96)$ & \\
\hline
\end{tabular}

Goodness-of-fit: $\mathrm{N}=22,787$; Hosmer-Lemeshow $(\mathrm{df})=5.92(8)$; P-value $=0.6559$

\begin{tabular}{|c|c|c|c|c|}
\hline Age strata & Covariates & Level & Odds Ratio & P-value (Wald) \\
\hline \multirow[t]{16}{*}{$45+\mathrm{yr}$} & Sex & & & $<0.0001$ \\
\hline & & Men & Ref & \\
\hline & & Women & $0.61(0.56-0.67)$ & \\
\hline & Deprivation & & & \\
\hline & & 1st Least & Ref & 0.0005 \\
\hline & & $2^{\text {nd }}$ & $1.36(1.18-1.57)$ & \\
\hline & & $3^{\text {rd }}$ & $1.23(1.07-1.43)$ & \\
\hline & & $4^{\text {th }}$ & $1.18(1.02-1.37)$ & \\
\hline & & 5th Most & $1.10(0.95-1.28)$ & \\
\hline & User category & & & 0.0007 \\
\hline & & Other & Ref & \\
\hline & & Light frequent & $0.76(0.65-0.89)$ & \\
\hline & Ethnicity & & & $<0.0001$ \\
\hline & & English & Ref & \\
\hline & & African & $1.61(1.31-1.97)$ & \\
\hline & & Celtic & $1.14(1.00-1.28)$ & \\
\hline
\end{tabular}




$\begin{array}{ll}\text { Eastern European } & 4.45(3.30-6.00) \\ \text { European other } & 1.62(1.25-2.10) \\ \text { Hispanic } & 3.49(2.91-4.20) \\ \text { Muslim } & 1.56(1.29-1.88) \\ \text { Other } & 2.00(1.68-2.37)\end{array}$


Table 3 Users not registered with a GP by names-based ethnicity (Onomap CEL Type). Groups with less than 25\% un-registered were aggregated in the 'Other' category.

\begin{tabular}{lccc}
\hline Names-based ethnicity (CEL Type) & Freq. & Total & Percent \\
\hline Poland & 723 & 1,424 & 50.8 \\
China & 140 & 325 & 43.1 \\
Russia & 56 & 182 & 30.8 \\
Greece & 64 & 215 & 29.8 \\
Germany & 140 & 475 & 29.5 \\
Spain & 679 & 2,458 & 27.6 \\
Italy & 497 & 1,832 & 27.1 \\
Hong Kong & 137 & 511 & 26.8 \\
Portugal & 713 & 2,665 & 26.8 \\
Albania & 39 & 152 & 25.7 \\
Norway & 74 & 291 & 25.4 \\
Balkan & 39 & 156 & 25.0 \\
Other & 6,700 & 43,180 & 15.5 \\
\hline England & 5,061 & 39,230 & 12.9 \\
\hline Total & 15,062 & 93,096 & 16.2 \\
\hline
\end{tabular}




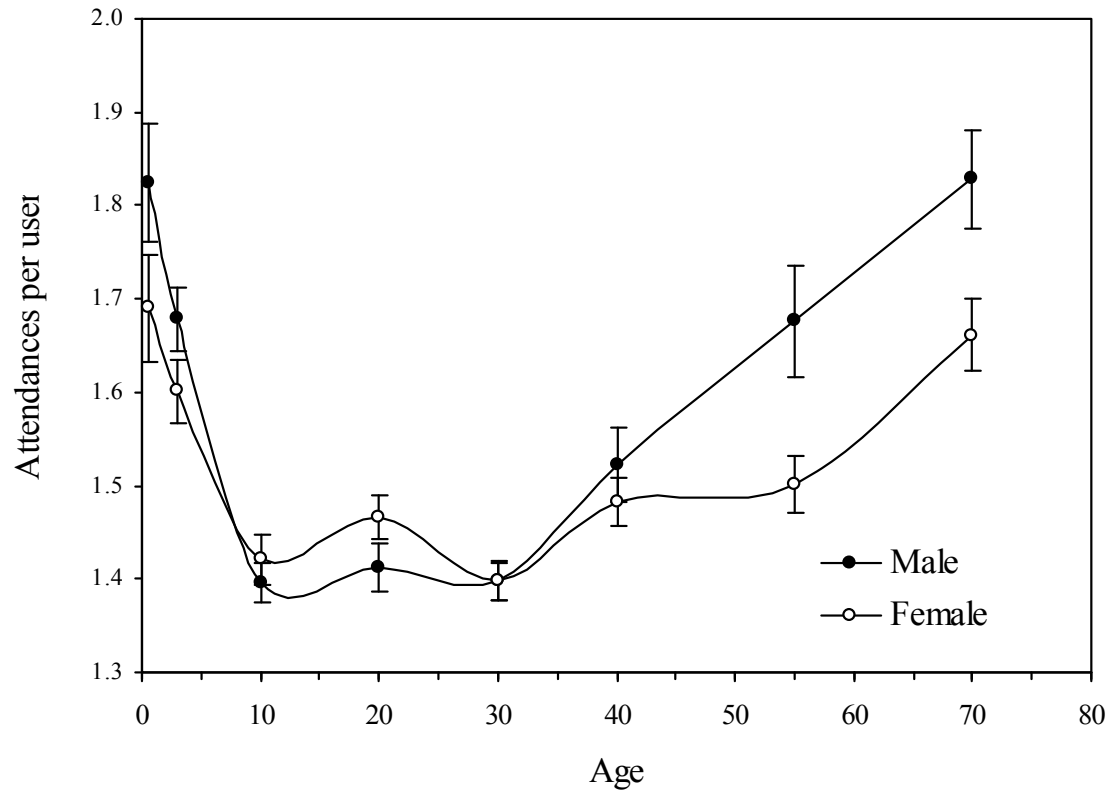

Figure 1 Light A\&E attendance rate by age and sex $(95 \% \mathrm{CI})$. 


\section{References}

Agran, P.F., Anderson, C., Winn, D., Trent, R., Walton-Haynes, L., Thayer, S., 2003. Rates of pediatric injuries by 3-month intervals for children 0 to 3 years of age. Pediatrics, 111, e683-692.

Aspinall, P. J., 2000. The mandatory collection of data on ethnic group of inpatients: experience of NHS trusts in England in the first reporting years. Public Health 114(4): 254-259

Delgado-Rodriguez, M., Llorca, J., 2004. Bias. Journal of Epidemiology and Community Health, 58, 635-641.

Gavrilov, L., Gavrilova, N., 2001. The reliability theory of aging and longevity. Journal of Theoretical Biology, 213, 527-545.

Gibin, M., Mateos, P., Petersen, J., Atkinson, P., 2009. Google maps mash-ups for local public health service planning. In: Geertman, S., Stillwell, J. (Eds) Planning support systems: best practice and proven methodologies. Springer Publishers, Berlin, pp. 227-242.

Giesen, P., Franssen, E., Mokkink, H., Bosch, W., 2006. Patients either contacting a general practice cooperative or accident and emergency department out of hours: a comparison. Emergency Medicine Journal, 23, 731-734.

Gill, L., 1997. OX-LINK: The Oxford medical record linkage system. In: Alvey, W., Jamerson, B. (Eds), Record linkage techniques, National Academy Press, Washington DC, pp. 15-33.

Hargreaves, S., Friedland, J.S., Gothard, P., Saxena, S., Millington, H., Eliahoo, J., Le Feuvre, P., Holmes, A., 2006. Impact on and use of health services by 
international migrants: questionnaire survey of inner city London A\&E attenders. BMC Health Services Research, 6, 153-160.

Haynes, R.M., Lovett, A.A., Bentham, G., Brainard, J.S., Gale, S.H., 1995. Comparison of ward population estimates from FHSA patient registers with the 1991 Census. Environment and Planning A, 27, 1849-1858.

Kendrick, D., Mulvaney, C., Burton, P., Watson, M., 2005. Relationship between child, family and neighbourhood characteristics and childhood injury: a cohort study. Social Science, Medicine, 61, 1905-1915.

Kumarapeli, P., Stepaniuk, R., de Lusignan, S., Williams, R., Rowlands, G., 2006. Ethnicity recording in general practice computer systems. Journal of Public Health 28(3): 283

Lakha, F., Gorman, D., Mateos, P., forthcoming. Name analysis to classify populations by ethnicity in public health: Validation of Onomap in Scotland. Journal of Epidemiology and Community Health (in press)

Leaman, A.M., Rysdale, E., Webber, R., 2006. Use of the emergency department by Polish migrant workers. Emergency Medicine Journal, 23, 918-919.

Long, J.S., Freese, J., 2006. Regression models for categorical dependent variables using Stata College Station: Stata Press.

Mateos, P., 2007a. Classifying ethnicity using people's names. Proceedings to the Social Statistics and Ethnic Diversity Conference. Montreal: Quebec Inter-University Center for Social Statistics and the Institut National d'Études Démographiques. Mateos, P., 2007b. A review of name-based ethnicity classification methods and their potential in population studies. Population, Space and Place, 13, 243-263. 
Millett, C., Zelenyanszki, C., Binysh, K., Lancaster, J., Majeed, A., 2005. Population mobility: characteristics of people registering with general practices. Public Health, 119, 632-638.

Mladovsky, P., 2009. A framework for analysing migrant health policies in Europe. Health Policy, 93, 55-63.

Murphy, A.W., 1998a. 'Inappropriate' attenders at accident and emergency departments I: definition, incidence and reasons for attendance. Family Practice, 15, 23-32.

Murphy, A.W., 1998b. 'Inappropriate' attenders at accident and emergency departments II: health service responses. Family Practice, 15, 33-37.

Nanchahal, K., Mangatani, P., Alston, M., Dos Santos Silva, I., 2001. Development and validation of a computerized South Asian names and group recognition algorithm (SANGRA) for use in British health-related studies. Journal of Public Health Medicine, 23, 278-285.

Office for National Statistics, 2008. Key population and vital statistics. London.

Petersen, J., Atkinson, P., Petrie, S., Gibin, M., Ashby, D., Longley, P., 2009. Teenage pregnancy - new tools to support local health campaigns. Health and Place, 15, 300-307.

Rajpar, S. F., Smith, M. A., Cooke, M. W., 2000. Study of choice between accident and emergency departments and general practice centres for out of hours primary care problems. Journal of Accident and Emergency Medicine, 17: 18:21.

Raleigh, V. S., 2008. Collection of data on ethnic origin in England. British Medical Journal 337(aug21 1): a1107 
Sangowawa, O., Bhopal, R., 2000. Can we implement ethnic monitoring in primary health care and use the data? Public Health Medicine 2(3): 106-108

Sempere-Selva, T., Peiro, S., Sendra-Pina, P., Martinez-Espin, C., Lopez-Aguilera, I., 2001. Inappropriate use of an accident and emergency department: magnitude, associated factors, and reasons - an approach with explicit criteria. Annals of Emergency Medicine, 37, 568-579. 